\title{
Accreditation of health sciences institutions: Challenges and the road ahead
}

\author{
Subramoniam Rangaswami \\ Professor of Eminence in Medical Education \& Former Vice Chancellor, Sri Ramachandra Institute of Higher Education and Research, \\ Porur, Chennai, Tamil Nadu, India

\section{*Corresponding Author: Subramoniam Rangaswami} \\ Email: rangaswami43@gmail.com
}

“...The professional school must set and enforce its own standards, remembering that the greatest contribution it can make is to provide practitioners the intellectual tools to assess information critically, stay abreast with changing knowledge, adapt to continuous change, and reflect on the larger role and responsibilities of the profession in society."

Mechanisms for quality assurance and certification of consumer products have a long and chequered history. Rembrandt's 1662 oil painting captures an archival qualityassessment scene to great effect. ${ }^{2}$ Principles and policies for quality assessment and accreditation of higher education institutions are derived mostly from manufacturing and business practices.

The epochal transition the education of health sciences professionals in Europe and America in response to the socio-political changes following the French Revolution ${ }^{3}$ and the celebrated report of Abraham Flexner ${ }^{4}$ will similarly stand out as landmark events in the history of medical education. Other health sciences professions like Nursing have also recognized the relevance of these historic episodes in planning pedagogic strategies. ${ }^{5}$ It wouldn't be an exaggeration to suggest that policies for assessing the quality of education and research in health sciences in general and medical science in particular are to a large extent guided by the lessons learned from these.

The National Assessment and Accreditation Council (NAAC) established in 1994 has been involved in assessing and certifying quality and excellence in Higher Education including Health Sciences Education in the country. Institutional self-evaluation and peer evaluation form the sheet anchor in the NAAC accreditation process. NAAC introduced a significant shift in the methodology for assessing Health Sciences Institutions (Universities and Colleges) in July 2019. ${ }^{6,7}$ This was in keeping with similar changes introduced for General Universities and Colleges in July 2017 wherein quality assessment was made by systematic appraisal and quantification of objectively measurable quality parameters. This resulted in developing quantitative metrics separately for system-generated scores and qualitative metrics for scores based on perceptual assessment by the visiting peer team $(70 \%$ and $30 \%$ respectively). In the case of Health Sciences institutions, the proportion of the metrics has been set as $65 \%$ and $35 \%$ respectively.

The Revised Assessment and Accreditation Framework (A \& A) of NAAC has been developed as a robust mechanism that is ICT-enabled, transparent and allows objectivity in quality assessment and embodies a significant paradigm shift. The seven Criteria reflecting the Vision, Mission and Core Values of NAAC continue to form the mainstay in the Revised Framework. In addition to the academic and administrative aspects of institutional functioning, information on emerging issues has also been included in the Revised Framework. In the manual for Health Sciences Colleges, specific metrics that reflect the teaching learning processes distinctive to individual disciplines have been incorporated. An added feature is the Student Satisfaction Survey wherein students are required to provide online feedback to a set of questions directly to NAAC. These, with the NAAC grades assigned on a sevenpoint scale (A++ to $\mathrm{C}$ ) makes it a formidable instrument for accreditation of Health Sciences Institutions.

\section{Challenges}

"Now there is no question at all that the education in attitude and skill that the physician obtains in medical school and in the hospital where he is an intern and resident is an absolute source of much of his performance as a practitioner." (Italics in the original). ${ }^{8}$

Eliot Freidson's observation above holds true in other health sciences professions also: such as Nursing, Dental Sciences, AYUSH and Allied Health Sciences. The challenge is to develop tools that would reflect the diverse teaching and learning needs and the methods followed as well as their outcome in quantitative terms. These include bed-side teaching, teaching in community settings and a whole range of clinical learning experiences in outpatient and inpatient departments, emergency room, operation theatres, ICU etc. Even more challenging is to measure the attainment of an essential set of core competencies by the students before the completion of their training. Here again, while it is practical to devise numerical scales for the attainment of cognitive and psychomotor skills, a similar approach is much less practical when it comes to attitudinal skills that include empathy, ethics and communication skills.

It will be a challenging experience for the participating institutions to prepare accurate responses for the quantitative metrics (QnM) that would entail exact interpretation by NAAC's ICT system and the Data Verification and Validation (DVV) team. Inclusion of mathematical formulae, Data Templates for the quantitative metrics and a table showing Standard Operating Procedures for Data Validation and Verification in the Manuals is expected to ease the difficulty to a large extent. 


\section{The road ahead}

Objective methods to measure quality standards of educational institutions have a lot to recommend. They certainly constitute a robust, transparent and tamper-proof mechanism. With increasing application of data-driven approaches in auditing the academic and administrative activities of Higher Education Institutions, our reliance on them as a secure and fail-safe ranking tool is likely to stay in the coming years. Be that as it may, it cannot be forgotten that it is just that - a measuring and ranking tool, a ranking framework. Seldom do we pause to consider the flipside. Recent studies suggest that the metrics used to rank institutions tend to follow Goodhart's Law which states: "when a measure becomes a target, it ceases to be a good measure" - the metrics themselves then become the targets. ${ }^{9}$ This, as the article by Fire and Guestrin suggests, is also true when one considers academic publishing metrics. ${ }^{10} \mathrm{~A}$ looming analogy with the legendary Procrustean bed may not be altogether out of place here.

Health Sciences Institutions in India are relatively young and are in the process of progressing towards operational maturity and organizational distinctiveness. Visiting Health Sciences Institutions for quality auditing will convince one how the leadership and faculty of many of these institutions are genuinely aspiring towards excellence. What they need is hand-holding, wherein experienced academics from senior institutions with a nuanced understanding of quality issues work with them as advisors and mentors enabling the realization of their aspiration for quality and growth. One possibility is to create consortia for institutional mentoring that would provide the much-needed incentive and inspiration for raising the quality standards and operational potential of these institutions.

The other mechanism is to encourage the process of benchmarking through institutional collaborations as a quality enhancement tool for change management. Several Higher Education Institutions across the world have adopted benchmarking practices for enhancing Higher Education System performance. Exemplar-referenced as well as criterion-referenced methods are followed for this. ${ }^{12}$ Several excellent reports on the subject are available in the literature. ${ }^{12-15}$ Benchmarking of Higher Educational Institutions is in its infancy in India. The possibility has been explored recently for Management Education in the country. ${ }^{16}$ The consortia for institutional mentoring mentioned above could consider benchmarking as one of the viable options for the handholding process.

Let data-driven quality assessment and numerical grading system stay with us; there is no question that they play a positive role in the quality assurance process. But let the system work in tandem with institutional mentoring and more cordial benchmarking systems that would help boost the quality standards of Health Sciences Institutions rather than remaining just a measuring and grading tool.
"Not everything that can be counted counts, and not everything that counts can be counted."

\section{W. Bruce Cameron}

\section{Conflict of Interest}

None.

\section{References}

1. Ludmerer K. Time to Heal: American Medical Education from the Turn of the Century to the Era of Managed Care (1999) Oxford University Press (p. 378).

2. Rembrandt (1662) Syndics of the Drapers' Guild (The Sampling Officials) www.rembrandt-van-rijn.com > syndicsof-the-drapers-guild.

3. Foucault M. The Birth of the Clinic: An Archaeology of Medical Perception Vintage Books 1994.

4. Flexner A. Medical Education in the United States and Canada: A Report to the Carnegie Foundation for the Advancement of Teaching. Bulletin No. 4. Boston, Mass: Updyke; 1910.

5. Gastaldo D, Holmes D. Foucault and nursing: A history of the present: Nursing Inquiry. 2000;6(4):231-40.

6. Manual of Health Sciences for Universities - NAAC. www.naac.gov.in > images > docs > Manuals > HSM-University

7. Unified Manual for Health Sciences Colleges - in RAF NAAC www.naac.gov.in > images > docs > Manuals > HSM-college

8. Freidson E. Profession of Medicine: A Study of the Sociology of Applied Knowledge Dodd, Mead \& Company 1970 (p.88)

9. Livan G. Don't follow the leader: how ranking performance reduces meritocracy. $R$ Soc Open Sci. 2019;6:191-255. http://dx.doi.org/10.1098/rsos.191255

10. Fire $M$ and Guestrin C. Over-optimization of academic publishing metrics: observing Goodhart's Law in action. Giga Sci 2019;8:1-20 doi: 10.1093/gigascience/giz053

11. OECD (2017), Benchmarking higher education system performance: Conceptual framework and data, Enhancing Higher Education System Performance, OECD Paris. https://www.oecd.org > education > skills-beyond-school > benchmarking-...

12. Scott R 2012 Benchmarking: A Literature Review - Edith Cowan University https://intranet.ecu.edu.au >__ data > assets > pdf file > Benchmarking-Lit...

13. Benchmarking in higher education: a study conducted by the Commonwealth Higher Education Management Service (UNESCO 1998) https://unesdoc.unesco.org > Notice

14. Booth S: Higher Education Pacific Quality Benchmarking Project 2017 https://ako.ac.nz > assets > reports > 2018-HEPQ > REPORT-Higher-Educa...

15. Sarialtin $\mathrm{H}$ Benchmarking as a quality assurance tool and its application to higher education (A conceptual framework). Online J Quality Higher Educ 2015;2(3). https://www.tojqih.net > journals > tojqih > sarialtin

16. Ravi B.S and Sumathi G. N (2014) Benchmarking Management Education in India. IOSR J Humanities Soc Sci (IOSR-JHSS) 2014;19(12):50-2e.

How to cite: Rangaswami S. Accreditation of health sciences institutions: Challenges and the road ahead. $J$ Educ Technol Health Sci. 2020;7(1):1-2. 